\title{
LEITURA SOBRE DIFERENTES DIMENSÕES DA VIOLÊNCIA E DA LEI E REFLEXÕES SOBRE POLÍTICA E EDUCAÇÃO, COM BASE EM SLAVOJ ZIZEK
}

\author{
Hildemar Luiz Rech ${ }^{1}$ \\ Fabiano Alves de Morais ${ }^{2}$
}

\begin{abstract}
Resumo
Em sua abordagem paraláctica da violência, Slavoj Zizek (2014) chama a atenção para as suas múltiplas dimensões, quais sejam: a simbólica, a sistêmica e a subjetiva. Já no que se refere à ambiguidade da Lei, cabe observar que no nível positivo do direito ela se encontra entrelaçada e comprometida com o poder do Estado. De outro lado, ao nível do inconsciente psíquico, ela emerge na forma de interdito inconsciente incondicional. Ainda, por outro lado, o ato político, enquanto ato de liberdade e de emancipação, não pede permissão a nenhum "grande Outro" disfarçado de legitimação/autorização liberal-democrática de nossos atos. Ao contrário, o ato se autoriza por si mesmo com base em sua própria Causa. Por fim, no que tange à educação, esta está em larga medida privatizada hoje, o que impõe o recuo da educação pública e universal. Assim, o ato pedagógico tem como desafio, uma práxis de ruptura e superação frente ao discurso e à prática do capital.
\end{abstract}

Palavras-chave: Zizek. Violência. Política. Lei. Educação.

\section{A READING ON DIFFERENT DIMENSIONS OF VIOLENCE AND LAW AND REFLECTIONS ON POLITICS AND EDUCATION, BASED ON SLAVOJ ZIZEK}

\begin{abstract}
In his parallactic approach of violence, Slavoj Zizek (2014) attracts attention to themultiples dimensions of violence, such as: a symbolic one, a systemic (or structural) one and a subjective one. In other perspective, with reference to the ambiguity of Law, it's appropriate to observe that, at positive level of right,the law find itself entwined and compromised with the power of the State. Starting yet from other point of view, at level of inconscious psyche, the law emerges as a form of inconditional inconscious interdict. Tackingyet one other perspective, we can say that the political act, as a freedom and emancipation act, doesn't ask for permission to any "big Other", disguisedas a liberal democratic legitimation/authorization content in our acts.On the contrary, the act authorize itself by himself, based on itsown cause. Finally, withreference to education, we must recognize that it's almost completely privatised today, imposing a regression to the public and universal education. Therefore, the educational act has, as a chalenge, a rupture and surpassing práxis in front of the discourse and the practice of capital.
\end{abstract}

Keywords: Zizek. Violence. Politic. Law. Education.

1 Doutor em Ciências Sociais pelo IFCH da UNICAMP, SP, com estágio doutoral pela Universidade de Manchester, Inglaterra; Pesquisador e Professor Titular no Departamento de Fundamentos da Educação e na Linha de Pesquisa de Filosofia e Sociologia da Educação no Programa de Pós-Graduação em Educação, FACED-UFC. Orcid: http://orcid.org/0000-0002-5825-1887. E-mail: hluizrech@ gmail.com.

2 Mestrando na Pós-Graduação no Departamento de Educação- FACED-UFC. Bolsista da CAPES, Graduação em Bacharelado em Filosofia; Instituto Teológico Pastoral do Ceará -ITEP. Licenciado em Pedagogia pela Universidade Estadual do Ceará-UECE; Licenciatura em Filosofia pela Universidade Estadual do Ceará-UECE; Especialista em Gestão e Supervisão Escolar. Instituto Teológico Metropolitano; Especialista em Gestão Pública Municipal - UECE. Orcid: https://orcid.org/0000-00018401-1249. E-mail: prof.fabianomorais@gmail.com. 
Para uma apresentação inicial do presente texto cabe observar que em seu desenvolvimento são sucintamente abordados alguns pontos cruciais das reflexões de Slavoj Zizek, tais como: a) a temática da violência com suas diferentes dimensões; b) a faceta público-positiva da lei; e c) a forma de seu interdito inconsciente; d) o conceito de ato político e a educação como ato pedagógico.

\section{Reflexões sobre diferentes dimensões da violência}

A violência nunca deve, em sua complexidade, ser vista de modo reducionista como mera violência subjetiva, explicitamente absorvida em sua mera aparência, pois, em sua forma mais complexa e fundamental a violência jamais se restringe isoladamente o seu aspecto físico diretamente visível. A violência física direta, que se circunscreve apenas a uma "passagem ao ato" (acting out) avessa ao simbólico, exprime nada mais que uma atitude reativa que mantém as coordenadas sistêmicas do capital intactas. Assim, sob o aspecto meramente subjetivo a violência exprime uma forma de total impotência política (ZIZEK, 2014).

Por outro lado, para que a violência possa ser revolucionária ela deve inserirse no combate permanente contra a cristalização ou ossificação das estruturas do Estado imbricada com a dinâmica sistêmica intrínseca ao capitalismo. Nesta perspectiva, também é imprescindível que se estabeleça uma dissolução de todas as formas de vida ditadas pela reprodução capitalista. Enfim, isto implica em que os indivíduos com sua subjetividade consigam lidar com a difícil situação de sustentar-se, em um momento de rompimento com o discurso capitalista com sua rede simbólica alienante - ancorado em significantes mestres alienantes (ZIZEK, 2010). Assim, apenas depois da consolidação de um rompimento efetivo, podem prevalecer novos significantes mestres e novas insígnias simbólicas, em termos de conteúdo subjetivo, sintonizados com uma perspectiva social e política afinada com um processo de emancipação individual e coletiva.

A abordagem crítica da violência de parte do filósofo esloveno também apresenta uma afinidade eletiva com o pensamento de Walter Benjamin (2011), tanto que para ele a violência fundamental que assegura o funcionamento normal do Estado é a violência mítica, assim como concebida pelo filósofo berlinense.

O caráter mítico da violência ancora-se na violência sistêmica, que se encontra estruturalmente inscrita, de modo oculto, na dinâmica contraditória da economia, das relações sociais e do próprio estado capitalista. Enfim, a violência mítica

\begin{tabular}{|c|c|c|c|c|}
\hline Qevista Dialactus & Ano 10 & n. 24 & Setembro - Dezembro 2021 & p. $197-215$ \\
\hline
\end{tabular}


e a violência sistêmica se apoiam na lei do valor trabalho; na forma da mercadoria dinheiro enquanto equivalente geral de todas as relações de troca no mercado; na acumulação ampliada do capital; e, enfim, nas formas de intervenção do estado para manter a assimetria capitalista nas relações de classe e de poder, tanto nas esferas social e política. Portanto, no que tange à violência sistêmica, cabe observar que os agentes estatais, em relativa afinidade com os agentes do capital, atuam de modo brutalmente repressivo e reativo quando se trata de proteger as regras sistêmicas da modelo dominante vigente.

Para Zizek (2014), também a ideia benjaminiana da violência divina é a forma fundamental de violência capaz de minar e romper com os significantes mestres que estruturam a rede simbólica alienante de toda organização estatal autoritária e opressiva entrelaçada com as coordenadas estruturais da violência sistêmica do capitalismo.

Enfim, sob o prisma de Zizek (2014), há fundamentalmente três dimensões distintas de violência, quais sejam: a) a do campo simbólico da linguagem; b) a da estrutura sistêmica de base histórico-social; e c) a da própria subjetividade humana. Portanto, é a partir de uma complexa multiplicidade paraláctica de pontos de incidência que Zizek aborda a noção de violência a partir destas três dimensões cruciais.

Primeiro temos, segundo o autor (2014), uma violência simbólica que é o tipo mais decisivo e fundamental de violência. Esta dimensão da violência encarna a linguagem e suas formas, desde o cerne do registro simbólico. E, como tal, ela envolve os significantes mestres e os significantes do saber, que se exprimem via sujeito da enunciação inconsciente, os quais, porém, incidem sobre a conformação de um determinado universo de significado que, ademais, é socialmente construído e, sob este aspecto, relacionado ao sujeito do enunciado. A violência simbólica, exercida pela classe dominante - mediante um discurso de controle ideológico-hegemônico atado à reprodução ampliada do Capital e de suas relações sociais de produção -, impacta sobre a identidade das classes e frações da classe dominadas e exploradas. Da mesma forma, segundo Zizek (2014), o discurso racista, de que os negros são inferiores aos brancos, afeta e cerceia a identidade sócio simbólica dos negros, tornando os negros realmente inferiores na sociedade, de modo que a violência exercida mediante a linguagem é efetiva e eficiente. Enfim, a violência simbólica que se articula a partir das próprias estruturas da linguagem, além de incidir sobre as práticas econômicas de reprodução social, funciona, portanto, também como dispositivo ideológico discursivo extra econômico que costura e amarra a reprodução sociocultural e sócio-política na sociedade capitalista. Esta função

\begin{tabular}{|l|l|l|l|l|}
\hline Qenista Dialectus & Ano 10 & n. 24 & Setembro - Dezembro 2021 & p. $197-215$ \\
\hline
\end{tabular}


extra econômica exercida mediante diversos dispositivos de violência simbólica é algo indispensável à dinâmica contemporânea do capitalismo globalizado, pois este não conseguiria completar o seu ciclo de reprodução social, sem o apoio em dispositivos normativos, burocrático-institucionais, midiáticos e tecnológicos de dissuasão, convencimento e controle; e sem a ancoragem em mecanismos, estratégias e práticas de cunho ideológico, político e cultural.

Ainda referente a esta dimensão da violência simbólica, cabe observar que:

Quando percebemos algo como ato de violência, o medimos por um padrão pressuposto do que seja a situação 'normal' de não violência - e a maior forma de violência é a imposição desse padrão, com base no qual alguns eventos aparecem como "violentos". É por isso que a linguagem em si, o próprio meio da não violência, de reconhecimento mútuo, envolve uma violência incondicional (ZIZEK, 2010, p.50).

Para Lacan, a linguagem não é primordialmente criação e instrumento do homem, pois antes é este último que se debate nela. Segundo Zizek (2010, p.52):

\begin{abstract}
A virada 'paranoica' de Lacan, seu aperto adicional no parafuso freudiano, advém da caracterização dessa casa como casa de tortura: 'A luz da experiência freudiana, o homem é um sujeito pego e torturado pela linguagem (...), como também se debate numa casa de tortura da linguagem: toda a psicopatologia descrita por Freud, dos sintomas-conversões inscritos no corpo até os colapsos psicóticos totais, são cicatrizes dessa tortura permanente. Todos eles são sinais de uma original e irremediável lacuna entre sujeito e linguagem, todos eles são sinais de que o homem não pode jamais estar em casa em sua casa [no edifício da linguagem].
\end{abstract}

Mas, desde seu núcleo central, o aspecto torturante da linguagem, no edifício lacaniano, diz respeito às vicissitudes da libido do sujeito e é isso que abre espaço para o Real do gozo (da jouissance) com toda sua tonalidade de excesso e sofrimento. Além disso, a linguagem, simultaneamente que exige a passividade do sujeito - para deixar nele, inclusive em seu corpo, a sua marca - envolve a resistência permanente desse sujeito. Ou seja, este último não se adapta, rebela-se e debate-se com a linguagem, a ponto de incansavelmente emergir como "um espinho na garganta dos significantes", enfim na cadeia da linguagem (ZIZEK, 2010).

Enfim, para Lacan, segundo Zizek, é preciso, antes de tudo, captar o aspecto do “(...) impacto propriamente traumático da passividade mesma do ser do sujeito capturado na linguagem, a tensão entre o animal humano e a linguagem. Existe o 'sujeito' porque o animal humano não se ‘encaixa' na linguagem” (ZIZEK, 2010, p.53). 
Assim, para Zizek (2010), o estatuto do sujeito torturado e mutilado de Lacan é real. E isso envolve inclusive o 'real da castração do sujeito', de modo que a própria constituição do sujeito e a própria vida do sujeito, são apanhados pelo 'real traumático'.

No que se refere a esta coisa real da castração cabe observar que ela é, em última análise, este núcleo impossível do sujeito, ou seja, impossível de ser representado ou simbolizado. Desse modo, como observa Zizek (2010, p.54): “É necessário aplicar ao sujeito a definição da Coisa como '/parte, aspecto/ do real que sofre do significante' - a dimensão mais elementar do sujeito não é a atividade, mas a passividade, o sofrimento".

Mas, o sujeito enquanto 'uma partícula vazia do real', que se debate com a linguagem não se adapta ao modo da inscrição torturante da linguagem na carne:

\begin{abstract}
Para que “(...) a transposição da realidade biológica imediata do corpo para o espaço simbólico ocorra, é necessário que se deixe uma marca de tortura no corpo sob as vestes de sua mutilação. Assim, não é suficiente dizer que 'a palavra se fez carne'. O que se deve acrescentar é que, para que a Palavra se inscreva na carne, uma parte da carne - a proverbial libra de carne shylockiana - tem que ser sacrificada. Já que não há harmonia pré-estabelecida entre Palavra e carne, é somente por meio de tal sacrifício que a carne se torna receptiva para a Palavra" (ZIZEK, 2010, p.54).
\end{abstract}

Por outro lado, como observa Zizek (2010), a própria linguagem, para dizer a verdade, deve passar por um processo de tortura. Ou seja:

\begin{abstract}
Ela deve ser torcida, desnaturalizada, estendida, condensada, cortada e reunida, posta a trabalhar contra si mesma. A linguagem como "grande Outro" [ou seja, como ancoradouro inconsciente de significantes mestres e comuns, interrelacionados com dispositivos institucionais e normativos que alienam e apassivam a subjetivação HLR] não é um agente de sabedoria a cuja mensagem devemos nos conformar, mas o lugar de cruel indiferença e estupidez. A forma mais elementar de se torturar a linguagem de alguém se chama poesia. Imaginem o que uma forma complexa como um soneto faz com a linguagem. Ela força a fluidez livre do discurso a adequar-se a um 'leito de Procrusto' de formas fixas de ritmos e rimas... (ZIZEK, 2010, p.53).
\end{abstract}

Uma segunda dimensão da violência, segundo Zizek (2014), se exprime como violência sistêmica, que aparentemente é menos visível, mas que é crucial para se captar a complexa articulação com as demais formas ou dimensões da violência. Esta forma de violência é inerente ao que imaginariamente é percebido como estado normal e pacífico das coisas. A propósito, a violência sistêmica deve ser compreendida a partir de um lastro estrutural e histórico. Ela é relacionada às próprias coordenadas sistêmicas da ordem social capitalista moderna e contemporânea e à sua dinâmica histórica. 
O fetichismo da mercadoria e da mercadoria-imagem e o crescente poder do capital financeiro, em sua articulação com o capital industrial-produtivo, com o setor de serviços e com a dinâmica da sociedade de consumo, são elementos que incidem constrangedoramente sobre as práticas sociais cotidianas na atualidade. Estes, portanto, são importantes aspectos da violência sistêmica.

As coordenadas sistêmicas apresentam ainda outra dimensionalidade estrutural oculta e contraditória fundamental de antagonismo social que é a "luta de classes". Esta divisão social fundamental exerce uma força de conformação e de lapidação sobre as demais diferenças sociais, étnicas, raciais, de gênero, religiosas e culturais. Enfim, este núcleo estrutural contraditório funciona com uma divisão social e política sistêmica anônima, que superdetermina o arranjo dinâmico das relações de exploração e dominação social e a relação política de forças na sociedade (ZIZEK, 2014).

Uma terceira dimensão da violência, visualizada por Zizek (2014), é a violência subjetiva, que é a mais visível das formas de violência. Mas a qual é apanhada de forma equívoca quando não abordada a partir da articulação complexa que a envolve com as demais dimensões da violência, quais sejam, a simbólica e a objetiva sistêmica. O elemento que a caracteriza é o fato de ela se exprimir mediante os atos de determinados agentes sociais explicitamente identificáveis, que perturbam o aparente estado normal e pacífico das coisas no contexto sócio-político da sociedade.

Desse modo, segundo Zizek (2014), a violência subjetiva se articula em torno de práticas sociais autoritárias (ou agressivas) fundamentalistas, envolvendo turbas fanáticas. Ademais, ela também pode se configurar a partir de agentes sociais engajados em aparelhos repressivos disciplinados, ou a partir de associações privadas legais e ilegais que espalham ações violentas que provocam o terror e o medo. Ela pode, igualmente, emergir como atos violentos com motivações criminosas, perpetrados por indivíduos malévolos. Enfim, ela pode ainda brotar enquanto atos isolados de violência, com traços de "anormalidade" ou patológicos; ou, mesmo, enquanto práticas reativas de ressentimento e de desespero social, sem nenhuma visualização alternativa ou revolucionária de sociedade. Enfim, é fundamental que não se visualize a violência subjetiva como um fetiche. Ao contrário, a tarefa central é compreender a complexa interação das três dimensões da violência: a subjetiva, a objetiva e a simbólica.

Portanto, segundo Zizek (2014, p.17): 
A violência subjetiva é somente a parte mais visível de um triunvirato que inclui também dois tipos objetivos de violência. Em primeiro lugar há uma violência simbólica encarnada na linguagem e em suas formas (...). Essa violência não está em ação apenas nos casos evidentes - e largamente estudados - de provocação e de relações de dominação social que nossas formas de discurso habituais reproduzem: há uma forma ainda mais fundamental de violência que pertence à linguagem enquanto tal, à imposição de um específico universo de sentido. Em segundo lugar, há aquilo a que eu chamo de violência "sistêmica", que consiste nas consequências muitas vezes catastróficas do funcionamento regular de nossos sistemas, econômico e político.

A percepção aqui é paraláctica, pois as violências, objetiva e subjetiva, não podem ser apanhadas do mesmo ponto de vista: "A violência subjetiva é experimentada enquanto tal contra o pano de fundo de um grau zero de não violência. É percebida como uma perturbação do estado de coisa normal” (ZIZEK, 2014, p.17-18).

A violência objetiva, em sua dimensão simbólica e sistêmica, apresenta um caráter oculto, funcionando de modo invisível, mas, conforme Zizek (2014, p.18):

É precisamente ela que sustentam a normalidade do nível zero contra a qual percebemos algo como subjetivamente violento. Assim, a violência sistêmica é algo parecido com a célebre 'matéria escura' da física, a contrapartida de uma violência subjetiva (demasiado) visível.

Em vez de abordar diretamente a violência subjetiva, em suas formas de explosão irracional, é mais adequado, em tentativas de interpretação explicativa, que a miremos de modo oblíquo em sua manifestação. Pois, qualquer consideração direta é sempre mistificadora. Sob este prisma, segundo Zizek (2014, p.19):

\begin{abstract}
A alta potência do horror diante dos atos violentos e a empatia com as vítimas funcionam inexoravelmente como um engodo que nos impede de pensar. Uma abordagem conceitual desapaixonada da tipologia da violência deve, por definição, ignorar o seu impacto traumático. Apesar disso, em certo sentido uma análise fria da violência reproduz o seu horror e dela participa. É necessário distinguir, ainda, entre verdade (factual) e veracidade: o que torna verídico o testemunho de uma mulher estuprada (ou de qualquer outra narração de um trauma) é a sua incoerência factual, sua confusão, sua informalidade. Se a vítima fosse capaz de descrever sua experiência dolorosa e humilhante de maneira clara, apresentando todos os dados de uma forma consistente, esta clareza poderia levar-nos a suspeitar de sua veracidade. Aqui, o problema é parte da solução: as deficiências factuais do relato do sujeito traumatizado quanto a sua experiência confirmam a veracidade do testemunho, uma vez que indicam que o conteúdo descrito "contaminou" o modo de sua descrição. (...) A única abordagem adequada do tema (...) será aquela que nos permita elaborar variações sobre a violência, mantidas a uma distância respeitosa em relação às vítimas.
\end{abstract}

Sob outro ângulo de análise é necessário, segundo Zizek (2014), levar em conta o caráter histórico, da violência sistêmica objetiva, ligado à configuração das 
coordenadas sistêmicas no quadro da emergência, do desenvolvimento e da dinâmica processual do capitalismo. Assim, hoje ocorre o impacto decisivo das características do capital virtual com a crescente presença do mercado de mercadorias e futuro e outras formas de especulação financeira.

Este quadro ilustra o império de "abstrações reais" em seu estado mais puro, que ultrapassam de longe, em termos de velocidade compulsiva autorreferente, a dinâmica destes fenômenos nos tempos em que Marx, pela primeira vez analisou com percuciência e argúcia a presença destas abstrações especulativas e fantasmagóricas. Embora, tenha sido Marx quem primeiro melhor captou a auto propulsiva e enlouquecida circulação do capital, cuja orientação solipsista atinge seu auge nas atuais especulações metarreflexivas sobre o futuro (ZIZEK, 2014).

Desse modo, "a forma mais extrema da ideologia não consiste em sermos tomados pela natureza espectral da ideologia, esquecendo as suas bases do âmbito dos indivíduos reais e de suas relações” (ZIZEK, 2014, p.26). Mas, consiste precisamente em subestimarmos ou até mesmo ignorarmos este "Real do espectral", ao nos dirigirmos diretamente às pessoas enquanto tais, com seus problemas concretos, sem levar em conta estas "abstrações fantasmagóricas” (ZIZEK 2014).

Como, nas trilhas de Marx, Zizek (2014, p. 25-26) escreve a este respeito:

\begin{abstract}
É demasiadamente simplista afirmar que o espectro desse monstro auto generativo, que segue seu caminho ignorando qualquer preocupação humana ou ambiental, seja uma abstração ideológica e que por trás dessa abstração há pessoas reais e objetos naturais, em cujos recursos e capacidades produtivas se baseia a circulação do capital, alimentando-se deles como um parasita gigante. O problema é que esta "abstração" não existe apenas na percepção distorcida da realidade social por parte de nossos especuladores financeiros, mas é "real" no sentido preciso em que determina a estrutura dos processos sociais materiais: os destinos de camadas inteiras da população e por vezes até mesmo de países podem ser decididos pela dança especulativa [autorreferente] do capital, que persegue seu objetivo de rentabilidade numa beatífica indiferença ao modo como tais movimentos afetarão a realidade social.
\end{abstract}

Portanto, a posição de Marx foi a de demonstrar como a dança teológica enlouquecida das mercadorias emerge dos antagonismos da vida social concreta. Ou seja, seu ponto de vista é a realidade social de produção material e a interação social não pode ser compreendida sem a dança metafísica autorreferente e auto propulsiva do capital que dirige o espetáculo. Pois, é esta que fornece a chave dos desdobramentos e das catástrofes que tem lugar na vida efetiva e concreta das pessoas: 
É aí que reside a violência sistêmica fundamental do capitalismo, muito mais estranhamente inquietante do que qualquer forma pré-capitalista direta de violência social e ideológica: essa violência não pode ser atribuída a indivíduos concretos e às suas más intenções, mas é puramente "objetiva", sistêmica, anônima. Encontramos aqui a diferença lacaniana entre a realidade e o Real: a "realidade" é a realidade social dos indivíduos efetivos implicados em interações e nos processos produtivos, enquanto o Real é a inexorável e "abstrata" lógica espectral do capital que determina o que se passa na realidade social (ZIZEK, 2014, p.26).

Ainda sob este prisma, o capitalismo globalizado contemporâneo, para fazer frente à sua crise de legitimidade e de acumulação ampliada, necessita recorrer a sutis e sofisticadas formas adicionais de dominação político-social, para manter em movimentação acelerada a dinâmica dos fluxos do mercado. E, em um quadro de afirmação do paradigma tecnológico da automação e da digitalização no cerne do capitalismo global - com suas práticas de gestão flexível; seus mecanismos financeiros de concentração da riqueza; suas ações competitivas corporativista-organizacionais; e sua centralização produtiva desverticalizada, com seu fluxo de conhecimentos e informações no circuito interno das grandes organizações empresariais -, uma das estratégias mais adotadas é o consumismo artificialmente induzido a crédito, sob a emulação do reino da mercadoria-imagem, da propaganda, do marketing e da marca dos produtos. Enfim, as práticas sociais capitalistas apoiam-se no fetichismo da mercadoria imagem e na lei do valor como seu núcleo articulador e dinamizador.

O capitalismo contemporâneo - pautado em bases fortemente cognitivistas se caracteriza, ademais, pelo foco na produção e no controle de informações, pela valorização da produção do conhecimento e pela circulação de mercadorias imateriais, além da manutenção da intensidade do mercado de troca de mercadorias materiais.

Entrementes, para garantir seu êxito, mecanismos extra econômicos de controle, sedução e alienação funcionam como elementos de captura da subjetividade dos indivíduos em prol da meta da reprodução ampliada do capital.

\section{Reflexões sobre a lacuna entre as encarnações positivas da lei e a injunção incondicional da lei/interdito que as apoia}

Segundo Zizek (2009a), diante da questão da violência da lei e do poder, não se pode desconhecer a novidade radical, para a abordagem de tal problemática, contida na concepção kantiana da Lei moral. Ou seja, a lei kantiana não é uma simples forma vazia que se aplica a um conteúdo empírico determinado a fim de assegurar que esse 
conteúdo encontre os critérios de adequação ética. Enfim, a forma vazia da Lei funciona antes como a promessa de um conteúdo ausente que nunca está por vir. Essa forma não é o molde neutro-universal da pluralidade dos diferentes conteúdos empíricos, mas atesta o fato de uma incerteza persistente quanto ao conteúdo dos nossos atos. Portanto, nunca sabemos se o conteúdo determinado, que presta contas da especificidade de nossos atos, será o correto, ou seja, nunca sabemos se agimos efetivamente de acordo com a Lei e não fomos guiados por motivações patológicas ocultas.

Enfim, segundo Zizek (2009a, p.362):

Kant anuncia assim a noção de Lei que encontra seu ponto culminante em Kafka e na experiência do moderno "totalitarismo" político: visto que no caso da Lei [onde o seu Dass-Sein (o fato da Lei) precede o seu Was-Sein (o que é essa Lei)] o sujeito encontra-se numa situação em que, apesar de saber que existe uma Lei, ele nunca sabe (e a priori, nunca pode saber) o que é essa Lei. [Pois há] uma distância exata que separa sempre a Lei das suas encarnações positivas. Por conseguinte, o sujeito é, a priori, na sua própria existência culpado: culpado, sem sequer saber de que se trata (e culpado por isso mesmo), [quando está] infringindo a lei sem sequer conhecer as suas regulações exatas. Segundo Zizek, o que temos aqui, e pela primeira vez na história da filosofia, é a afirmação da Lei como inconsciente: a experiência da Forma sem conteúdo é sempre indício de um conteúdo recalcado, ou seja, quanto maior for a intensidade com que o sujeito adere à forma vazia, mais traumático se torna o conteúdo recalcado.

Assim, essa ausência da Lei - enquanto um conjunto determinado de normas positivas universais - torna ainda mais forte a pressão insuportável "que a Lei moral exerce, na medida em que ela pressiona, como pura injunção vazia, para que cada um cumpra o seu Dever. Assim, (...) é aqui que encontramos a distinção crucial entre as regras a inventar e a Lei/Interdito que as apoia (ZIZEK, 2009a, p.363).

Sob este aspecto, Zizek (2014), portanto, aponta para a ambiguidade da Lei, destacando que, se no nível positivo do direito ela se encontra entrelaçada e comprometida com o poder do Estado, de outro lado, ao nível do inconsciente psíquico, ela emerge ainda sob outra faceta, na forma de interdito inconsciente incondicional.

Sob este último prisma, segundo Zizek (2009b, p.143):

[A lei se situa] ao nível subterrâneo do superego, [no qual] a mensagem pública de responsabilidade desdobra-se na mensagem obscena do exercício incondicional do poder: as leis não me atam de fato, pois eu posso fazer-vos o que quero; tratar-vos como culpados se assim decidir; destruir-vos com uma só palavra... Este excesso obsceno é um elemento constitutivo necessário à noção de soberania. A assimetria é aqui estrutural, ou seja, a lei não pode manter a sua autoridade se os sujeitos aí não ouvirem o eco da auto asserção obscena incondicional. E a violência divina do povo é correlativa deste excesso de poder. Ela é a contrapartida deste, dirigida completamente contra ele visando miná-lo. 
Portanto, quando a Lei falha em apresentar-se "como conjunto de normas universais simbólicas é que a encontramos na sua forma mais radical, a Lei sob o aspecto do Real de uma injunção incondicional" (ZIZEK, 2009a, p.363).

Segundo Zizek (2009a, p.363), se Kant for lido em termos psicanalíticos:

(...) A distância entre as regras que inventamos e a Lei que as sustém não é senão a distância entre regras (conscientemente pré-conscientes) que seguimos e a Lei como inconsciente: a lição básica da psicanálise é que, na sua forma mais radical, o Inconsciente não é a multiplicidade dos desejos ilícitos "reprimidos", mas $a$ própria Lei fundamental.

Sob este aspecto, mesmo um sujeito bastante narcísico é apoiado, em termos de seu uso dos prazeres, "pela injunção incondicional inconsciente de um superego que lhe ordena que goze" (ZIZEK, 2009a, p.363).

Por conseguinte, o sujeito, quando infringe a lei sem conhecer efetivamente as determinações dessa lei, sente-se culpado, ou seja, sofre uma recriminação interna que lhe traz um forte mal-estar. Em decorrência disso, segundo Zizek (2008), é preciso que se estabeleça uma cisão entre a Lei pública e seu complemento superegóico obsceno, pois, é isso que nos faz confrontar o próprio âmago da paralaxe político-ideológica:

A lei pública e seu complemento superegóico não são duas partes diferentes do edifício legal, são o mesmo e o único "conteúdo" - com uma pequena mudança de ponto de vista, a Lei digna e impessoal assemelha-se a uma máquina obscena de jouissance (gozo). [E com] outra leve mudança (...) [o que ocorre é que] as regulações legais, que prescrevem nossos deveres e garantem nossos direitos, parecem ser a expressão de um poder impiedoso cuja mensagem a nós, súditos, é: "Posso fazer o que quiser com vocês!" (ZIZEK, 2008, pp.437-438).

O mestre inimitável dessa mudança paraláctica em relação ao edifício do poder legal foi Kafka. Foi ele que percebeu “(...) uma máquina gigantesca de gozo obsceno no que antes parecia um digno edifício da Ordem legal” (Zizek, 2008, p.438).

Ademais, ainda nesta perspectiva de análise, segundo Zizek (2014, p.78):

O verdadeiro contrário do amor-próprio egoísta não é o altruísmo, a preocupação com o bem comum, mas a inveja, o ressentimento, que me faz agir contra os meus próprios interesses. Freud sabia muito bem disso: a pulsão de morte opõese tanto ao princípio de prazer como ao princípio de realidade. $\mathrm{O}$ verdadeiro mal, que é a pulsão de morte, implica a auto sabotagem. Faz com que ajamos contra os nossos próprios interesses.

A propósito, nas palavras de Zizek (2014, p.78), o problema do desejo humano é, no sentido lacaniano, ser sempre “desejo do Outro", em todos os sentidos do 
termo: “desejo pelo Outro, desejo de ser desejado pelo Outro, e, especialmente, desejo daquilo que o Outro deseja. Este último desejo torna a inveja, que inclui o ressentimento, uma componente constitutiva do desejo humano".

Por outro lado, ainda segundo Zizek (2014), tanto Kafka, quanto a psicanálise lacaniana nos alertam para a existência de uma máquina gigantesca de mais-gozar obsceno, a qual se imbrica, sob um mesmo e único "conteúdo", com as formas públicas da lei no cerne do mesmo edifício legal. Portanto, desse modo, a Lei digna e impessoal enlaça-se com uma máquina obscena de gozo, implicando o excesso da pulsão de morte. Assim, a própria psicanálise reintroduz de modo pertinente as noções do mal e da responsabilidade no discurso ético, nos lembrando que é a "pulsão de morte" que nos perturba ao buscarmos de modo racional o prazer, funcionando como uma estranha inversão que nos levam a sabotar nossos próprios interesses. Ainda nesta mesma direção cabe observar que, sob o signo da inveja, a exigência de justiça é que o gozo excessivo do Outro seja limitado, do modo que todos tenham um acesso igualitário ao gozo. A propósito, o sujeito não inveja a posse pelo Outro do objeto investido, enquanto tal. Antes a inveja dirige-se mais ao modo como o Outro é capaz de gozar o seu objeto, e é por isso que não basta roubar o objeto ao Outro, devendo o verdadeiro alvo dirigir-se à destruição da aptidão/capacidade do Outro de gozar o objeto.

Como observa Zizek (2014, p.79-80):

\begin{abstract}
O desfecho necessário desta exigência é, evidentemente, o ascetismo. Uma vez que não é possível impor uma jouissance [Gozo] igual, o que é imposto - em vez de uma igual partilha - é a proibição. Hoje, na nossa sociedade alegadamente permissiva, esse ascetismo, contudo, assume a forma do seu contrário, isto é, a de uma injunção superegóica generalizada - o mandamento que nos intima: "Goze". Estamos todos enfeitiçados por tal injunção. O resultado é que nosso gozo nunca foi tão tolhido. Pensemos no [ascetismo hedonista do] yuppie que combina a "auto-realização" narcísica com essas disciplinas extremamente ascéticas que são praticar corrida [o jogging], alimentar-se de forma saudável, etc.
\end{abstract}

Sob esta perspectiva, pode aqui também ser relembrada a leitura de Antígona proposta por Lacan, na qual se insere a chave do seu "Kant com Sade. A propósito, segundo Zizek (2014, p.152-153):

Hoje, na nossa era pós-idealista da "hermenêutica da suspeita", não sabemos todos que a chave do avec ("com”) [do Kant com Sade] está em significar que a verdade do rigorismo ético de Kant é o sadismo da lei - ou seja, que a lei kantiana é uma instância superegóica que goza sadicamente o impasse do sujeito, a sua incapacidade de corresponder às suas exigências inexoráveis, à semelhança das 
do proverbial professor que tortura os alunos fixando-lhes tarefas impossíveis e secretamente saboreia os seus fracassos? E todavia, o que Lacan nos diz é exatamente o oposto dessa primeira associação: não era Kant um sádico disfarçado, mas Sade é que era um kantiano disfarçado. O que significa que devemos ter em mente que o tema fulcral de Lacan é sempre Kant, não Sade: o que lhe interessa são as consequências últimas e as premissas negadas da revolução ética kantiana.

Ou seja, Lacan não apresenta afinidade com posições reducionistas que vêem qualquer ato ético como tendo por origem uma motivação patológica. De modo bem diferente, como observa Zizek (2014, p.153):

O tema fulcral do interesse de Lacan reside antes na inversão paradoxal, através da qual o próprio desejo (ou seja, o agir segundo o nosso próprio desejo, sem o comprometer) não pode mais ter por origem qualquer interesse ou motivação de ordem "patológica". E por isso corresponde aos critérios do ato ético kantiano, de tal modo que "seguir o próprio desejo" coincide com "fazer o próprio dever". É por isso que Lacan, na sua concepção do ato, inverte a "hermenêutica da suspeita" estabelecida: quando o próprio Kant, movido pela suspeita, admite que nunca podemos saber ao certo se o que fizemos foi um verdadeiro ato ético, não sustentado em segredo por algum motivo patológico (ainda que esse motivo seja a simples satisfação narcísica decorrente do fato de termos feito o nosso dever), incorre então em erro. O que é verdadeiramente traumático para o sujeito não é o fato de um puro ato ético ser (talvez) impossível, de a liberdade ser (talvez) uma aparência, baseada na ignorância das verdadeiras motivações dos nossos atos; o que é verdadeiramente traumático é a própria liberdade, o fato de que a liberdade é possível, e de nós procurarmos desesperadamente estas ou aquelas determinações "patológicas" a fím de evitarmos este fato. Para dizê-lo de outra forma, a verdadeira teoria freudiana nada tem a ver com a redução da autonomia ética a uma ilusão baseada na repressão dos nossos "baixos" motivos libidinais.

Enfim, quando concebemos o ato ético para além do princípio de realidade, nos confrontamos com o "realismo" pós-moderno cuja posição inerente é que a realidade é apenas: “(...) o resultado de certo conjunto historicamente específico de práticas discursivas e mecanismos de poder. Aqui a crítica ideológica das ilusões em nome da realidade é universalizada e invertida em seu oposto: a própria realidade é a ilusão suprema" (ZIZEK, 2013, p.116).

Sob esta perspectiva, segundo Zizek (2013, p.117):

A lição que tiramos desse paradoxo diz respeito à oposição entre realidade e Real: desprovida do núcleo duro do Real, daquilo que resiste à simples integração na realidade comum (simbolização, integração em nosso universo), a própria realidade se transforma em uma tessitura maleável, indefinidamente plástica, que, precisamente, perde o caráter da "realidade" e se transforma em efeito fantasmático das práticas discursivas. E - o anverso do mesmo paradoxo - a experiência definitiva do Real não é da "realidade" que destrói as ilusões, mas a de uma "ilusão" que persiste "irracionalmente" contra a pressão da realidade, não cedendo à "realidade". 
Assim, conforme Zizek (2013), não é porque as pessoas não conseguem aceitar a dura realidade e precisam de falsos sonhos é que a ilusão tem um futuro. Mas, na perspectiva de Freud - em seu O futuro de uma ilusão - o que garante a continuidade futura de uma ilusão é que as "ilusões" são sustentadas pela insistência incondicional de uma pulsão. A qual é mais real que a própria realidade.

\section{Breves reflexões sobre "ato político" e educação}

Nesta situação de paralisia, Zizek (2005) coloca a necessidade de que se instaure a emergência do autêntico ato político para que se concretize uma efetiva ruptura com as coordenadas da ordem social violenta e injusta.

Sob este prisma, segundo Zizek (2005), o ato político somente pode ocorrer no momento em que o pensamento e a ação do sujeito se desprendem das coordenadas da rede simbólica alienante, e se atarem à atividade coletiva, traduzindo-se em uma ação política soberana, sem fixação institucional imediata à intervenção política. Assim, o ato político instaura sua própria legalidade, suspendendo a Lei do poder opressor imperante, abrindo desta maneira espaços para a instauração qualificada de um processo de emancipação econômico-social, cultural e política.

Esta leitura de Zizek a respeito do ato político não encarna, a princípio, nenhuma substância positiva inicial. Ela, parte, antes da irredutibilidade negativa do inconsciente que no sujeito se define por resistir aos processos de identidade e de autorreflexão. Portanto, este prisma analítico, se ancora no descentramento do sujeito do inconsciente: "Descentramento, que indica a posição de não-identidade que um conceito não substancial de sujeito sempre sustentará diante dos espaços de representação, de auto apreensão reflexiva e de identificação social" (SAFATLE, 2003, p.182).

Na perspectiva de Zizek o sujeito denota uma partícula de liberdade, de modo que ele é intrinsecamente político, se encontrando em uma situação sempre aberta de inadequação, de superação, enfim de transcendência: "O sujeito é aquilo que nunca é totalmente idêntico a seus papéis e identificações sociais" (SAFATLE, 2003, p.183).

As políticas de identidade acabam também fazendo o jogo da ideologia e, por conseguinte, do capital. Pois, o capital acomoda-se muito bem às políticas de identidade e à multiplicidade de identidades. Sob este aspecto, a negatividade, na forma de uma universalidade não substancial e na forma de não-adequação pode contrapor-se à falsidade da universalização da política da identidade. 
O próprio ato político não rima com a ideia de identidade, mas com a violência redentora bejaminiana contraposta à violência instituída de forma velada ou explícita:

\begin{abstract}
Há um abismo entre o 'fundamentalismo 'religioso [ou político] fanático e a intervenção revolucionária autêntica, ainda que ambos pareçam compartilhar um caráter radical. Esse abismo não se refere apenas à dimensão sócio-política, mas também à estrutura imanente do ato: o ato fundamentalista é realizado para o [gozo] do 'grande Outro'; nele o sujeito instrumentaliza-se [e imola-se] para o 'Outro'. [Já o ato político], como um ato autêntico se autoriza apenas em si - ou seja, ele não é coberto pelo 'grande Outro'; pelo contrário, intervém no ponto exato da inconsistência [deste último]. Essa distinção é a diferença [entre a falsa pureza do super eu obsceno e a pureza ética autêntica], entre Kant e Sade: Sade não é simplesmente a verdade de Kant; a posição perversa sadiana emerge, em vez disso, quando a postura ética kantiana radical está comprometida" (ZIZEK, 2005, p.261).
\end{abstract}

Enfim, sob este enfoque, todo ato político revolucionário é incondicional. Mas, não se trata de um "ato incondicional" situado fora da história e fora do simbólico, mas simplesmente de um ato surpreendente que é irredutível ao parâmetro e à moldura das condições dadas. Como destaca Zizek (2011a, p.311):

[O] ato não só está enraizado em suas condições contingentes, como são essas mesmas condições que fazem dele um ato: o mesmo gesto, realizado num momento errado - cedo ou tarde demais -, [deixa de ser, ou] não é mais um ato. Aqui o paradoxo propriamente dialético é que aquilo que torna o ato "incondicional" é sua própria contingência: se o ato foi necessário, isso significa que foi totalmente determinado pelas condições, e pode ser deduzido a partir delas (...). O vínculo entre a situação e o ato político, portanto, é claro: longe de ser determinado pela situação (...), o ato é possível em razão do não fechamento ontológico, (...) das lacunas de uma situação.

Enquanto ato de liberdade e de emancipação o ato político não pede permissão a nenhum "grande Outro" disfarçado de legitimação/autorização liberaldemocrática de nossos atos, ao contrário, ele se autoriza por si mesmo com base em sua própria Causa.

No que tange à educação, Zizek (2013) ressalta que esta, cada vez mais, está mergulhada em uma profunda crise. Pois, o seu papel institucional relacionado à socialização e à produção e reprodução de conhecimentos, tende a se restringir prioritariamente à oferta de uma aprendizagem de habilidades voláteis voltadas para 0 exercício de tarefas flexíveis ligadas a ocupações específicas, demandadas pelo mercado de trabalho capitalista. Assim, a educação passa a adequar-se integralmente ao status quo, 
ao mesmo tempo em que a ideia de uma cultura educacional qualificada e universal passa a ser completamente abandonada.

Ademais, conforme Zizek (2013), as gerações de professores - que no passado eram verdadeiros pensadores e debatedores públicos dos problemas econômicosociais, políticos e culturais - praticamente desapareceram. Estes professores foram substituídos por acadêmicos desencantadamente especialistas que trabalham de modo recluso e apático. Ou seja, as suas atividades não contemplam nenhum engajamento político efetivo, fora dos muros dos espaços acadêmicos. Ademais, seus discursos, além de estarem impregnados de jargões elitistas, estão embriagados por uma reflexividade racionalista reprodutora do sempre mesmo. A própria educação superior universitária perdeu o seu elo de conexão com a abordagem crítica das catástrofes sociais que afetam a maioria da população mundial, no cerne do capitalismo global contemporâneo.

Enfim, no atual contexto, segundo Zizek (2011), a educação privatizada e flexível substituiu em larga medida a educação pública e universal. O mercado invadiu a educação que antes era considerado domínio privilegiado do estado. E neste quadro - as práticas educacionais não correspondem mais aos interesses, às necessidades e às aspirações da maioria da população. Assim, cabe reinventar a educação radicalmente, pois a privatização do conhecimento intelectual e social e os processos de automação e digitalização produtivo-industrial e de serviços que também estão amplamente privatizados - acompanhados pela desverticalização, flexibilização e precarização das relações de trabalho -, podem desempregar e/ou sub-empregar em torno de $80 \%$ da força de trabalho mundial, de modo que uma educação que se restringe a atender as demandas do mercado capitalista é uma educação em profunda crise e deslocada dos graves problemas sociais que afligem a humanidade.

Por outro lado, a partir de uma perspectiva filosófica, o autêntico ato político e pedagógico, direcionado à emancipação individual e social, se reveste de uma autêntica radicalidade. Pois, não se trata de uma atividade falsa marcada pela impotência política que se restringe em de fato apenas reproduzir a constelação sócio simbólica do capitalismo global existente, mas se trata de uma ação política e educativa tencionada pelo Real impossível, capaz de instaurar um acontecimento, ou seja, capaz de efetivar uma autêntica ruptura com as coordenadas simbólicas e estruturais do status quo.

Ou seja, sob este prisma, todo ato político e pedagógico radical se localiza além de toda a sua condicionalidade, ou seja, ele é incondicional. Não se trata de um "ato 
incondicional" situado fora da história e fora do simbólico, mas simplesmente de um ato surpreendente que é irredutível ao parâmetro das condições opressivas dadas.

Enfim, segundo Zizek (2011), o ato educativo - que rima com o ato político direcionado à liberdade e à emancipação - somente pode ocorrer quando o pensamento e a ação do sujeito se desprendem das coordenadas da rede simbólica alienante (sintonizadas com a reprodução da forma social do capital) e se atam à atividade coletiva de emancipação. Somente, desse modo, eles podem traduzir-se em uma ação educativa e política soberana, sem fixação institucional imediata às imposições do "status quo". Ou seja, apenas assim eles estarão desatados das exigências pragmáticas de adaptação às diretrizes do poder constituído, as quais tendem a travar a emergência e a potência de uma linguagem, de um discurso e de uma práxis efetivamente de emancipação.

\section{Síntese conclusiva}

A violência apresenta, para Zizek (2014), três dimensões fundamentais - a simbólica, a sistêmica e a subjetiva - as quais apenas sob o prisma de um corte epistemológico e analítico podem ser abordadas de modo separado. As dimensões cruciais e decisivas da violência são a simbólica (relacionada à estrutura da linguagem e do discurso) e a sistêmica (relacionada ao cerne das coordenadas sistêmicas e históricosociais das formações econômico-sociais, políticas e culturais). Ambas, de modo imbricado, pré-definem o leque de escolhas econômicas, políticas e culturais disponíveis aos sujeitos. Por fim, temos a violência subjetiva, que é aquela que aparece de modo explícito, mas que só pode ser abordada de modo consequente com sua inter-relação com as outras dimensões da violência, quais sejam, a simbólica e a sistêmica.

Em referência à lei, Zizek (2008) observa que uma distância exata sempre separa a lei de suas encarnações positivas. Ou seja, a ideia de uma forma vazia da lei sem conteúdo remete à afirmação da lei como inconsciente e como indício de um conteúdo recalcado. Assim, a inexistência de um conjunto determinado de normas positivas universais torna a lei moral uma pura injunção vazia que pressiona cada indivíduo a cumprir seu dever. Segundo Zizek (2009a), a lei/Interdito inconsciente, sobre a qual se apoia toda e qualquer regra positiva a inventar, supõe uma distinção crucial e uma distância na forma de um hiato entre o conjunto positivo de leis simbólicas universais e a Lei enquanto interdito inconsciente. Como nos esclarece a psicanálise, o próprio Inconsciente, em sua forma mais radical, não é a multiplicidade dos desejos ilícitos 
"reprimidos", mas a própria Lei fundamental. A propósito, encontramos este interdito inconsciente como o Real traumático de uma injunção incondicional, sempre quando a Lei falha em apresentar-se como conjunto positivo de normas universais simbólicas.

Em decorrência disso, segundo Zizek (2008), é preciso que se estabeleça uma cisão entre a Lei pública e seu complemento superegóico obsceno, pois, é isso que nos faz confrontar o próprio âmago da paralaxe político-ideológica. Contudo, estas duas dimensões da lei não são duas partes diferentes do edifício legal, pois elas são o mesmo e o único "conteúdo". Ou seja, com um pequeno deslocamento de ponto de vista, a Lei digna e impessoal assemelha-se a uma máquina obscena de jouissance (gozo).

Enfim, no que se refere ao ato político e ao ato pedagógico radical cabe observar, segundo Zizek (2005; e 2011), que eles estão direcionados à emancipação. Mas, eles apenas podem ocorrer quando o pensamento e a ação do sujeito se desprendem das coordenadas da rede simbólica alienante - as quais estão sintonizadas com a reprodução da forma social do capital - e se atam à atividade coletiva de emancipação.

\section{Bibliografia}

SAFATLE, Vladimir. Posfácio: A política do real de Slavoj Zizek. In: ZIZEK, Slavoj. Bem-vindo ao deserto do real!: cinco ensaios sobre o 11 de setembro e datas relacionadas. São Paulo, Boitempo, 2003, pp.179-191.

ZIZEK, Slavoj. Violência: seis reflexões laterais. São Paulo, Boitempo, 2014.

. Alguém disse totalitarismo?: cinco intervenções no (mau) uso de uma noção. SP, Boitempo, 2013.

. O ano em que sonhamos perigosamente. São Paulo, Boitempo, 2012.

Em defesa das causas perdidas. São Paulo, Boitempo, 2011a.

. Primeiro como tragédia, depois como farsa. SP, Boitempo, $2011 \mathrm{~b}$.

. Linguagem, violência e não violência. In: Margem Esquerda - Ensaios Marxistas, nº14, São Paulo, Boitempo, 2010, pp.49-61.

D’Água Editores, 2009a.

. O sujeito incômodo: o centro ausente da ontologia política. Lisboa, Relógio . De la démocracie à la violence divine. In: Democracie, dans quel État? Paris, La Fabrique Ed., 2009b.

A visão em paralaxe. São Paulo, Boitempo, 2008.

\begin{tabular}{|l|l|l|l|l|}
\hline Revista Dialectus & Ano 10 & n. 24 & Setembro - Dezembro 2021 & p. 197 - 215 \\
\hline
\end{tabular}


Às portas da revolução: seleção de escritos de Lenin de fevereiro a outubro de 1917. São Paulo, Boitempo, 2005.

Bem-vindo ao deserto do real!: cinco ensaios sobre o 11 de setembro e datas relacionadas. São Paulo, Boitempo, 2003. 